\title{
Spectrophotometric quantification of phytic acid during embryogenesis in bambara groundnut (Vigna subterranea L.) through phosphomolybdenum complex formation
}

\author{
Takudzwa Mandizvo*, Alfred Oduor Odindo \\ Department of Crop Science, School of Agricultural, Earth and Environmental Sciences, University of KwaZulu-Natal, South Africa
}

\section{A B S T R A C T}

\begin{abstract}
In relation to seed vigour and hyperosmotic stress, phytic acid has implications in imparting drought tolerance and enrichment of seed mineral reserves respectively. The present study was undertaken to determine the variation in phytic acid during seed development and physiological maturity of 4 Bambara groundnut landraces. The landraces were grown in field during 2017-2018 rain season at Ukulinga, Pietermaritzburg. The phytate content was estimated indirectly from 14-65 days after flowering (DAF) by using a spectrophotometer, evaluating the total extractable phosphorus absorbance at $720 \mathrm{~nm}$. An analysis is described for the rapid determination of phosphorus in developing seeds. The colour complex (phosphomolybdenum) formed under acidic conditions absorbs maximally at $720 \mathrm{~nm}$ in acidic $(\mathrm{pH}<4.5)$ solutions. Absorbance of the chromophore when measured spectrophotometrically at $720 \mathrm{~nm}$, it obeys Beer's law over the range of 0 to $75 \mathrm{ppm}$ of standard phosphorus solution. There were significant differences $(\mathrm{P}<0.001)$ in total extractable phosphorus at 14 , 21 , 28, 35, 42 and 65 DAF. The highest and lowest extractable phosphorus was recorded in G340A and Kazai respectively. Pi seed content was between 1.51 and $5.69 \mathrm{mgkg}^{-1}$ at $14 \mathrm{DAF}$, at physiological maturity (65 DAF) Pi was recorded between 21.73 and $32.23 \mathrm{mgkg}^{-1}$. We drew conclusions that Bambara groundnut landraces may differ in both (1) phytic acid accumulation rate and (2) phytic acid content at physiological maturity. The results reported open the possibility of a specific seed selection criterion for improving the mineral element value of Bambara groundnut through the identification of landraces with high-Pi (phytic acid).
\end{abstract}

Keywords: Days after flowering; Beer's law; Embryogenesis; Inorganic phosphorus; Keggin ion; Phytic acid

\section{INTRODUCTION}

Phytic acid (myo-inositol 1, 2, 3, 4/5, 6-hexakis [dihydrogenphosphate]) is a common constituent of most legume seeds (Lehrfeld, 1994), with a significant nutritional role as the principal storage form of phosphorus $(\mathrm{P})$ and metal cations in seeds (Raboy, 2001). Iwai et al. (2012) alluded that, phytic acid has a strong binding affinity to both mono and divalent cations. During the onset of seed embryogenesis, plants remobilize and transport nutrients distributed throughout the vegetative source organs to developing seeds (Martínez-Ballesta et al., 2020). Mature seeds contain large amounts of phosphorus (P) in an organic form stored in form of InsP, which supports growth during the early stages of seedling establishment (Mandizvo and Odindo, 2019). During germination, phytate is catabolized by hydrolysis reaction catalyzed by phytase, releasing inorganic phosphates (Pi), inositol, and various minerals from the phytate (Bohn et al., 2007).

A novel role in plant seed physiology can be assigned to phytic acid, that is, protection against oxidative stress during the seed's life span. Oxidative stress affects seeds, during the last phase of maturation when seed tissues undergo desiccation accompanied by oxidative stress (Bailly, 2004). In maize (Zea mays) seeds Pilu et al. (2005) endowed antioxidant properties of phytic acid against reactive oxygen species, this was consistent with the progressive decrease observed by (Doria et al., 2009) in antioxidant reserves during seed storage and ageing. Therefore, phytic acid can prove to play a major role in maintaining seed quality by protecting embryo viability. There is an increasing interest in the measurement of antioxidants in seeds. This

Corresponding author:

Takudzwa Mandizvo, Department of Crop Science, School of Agricultural, Earth and Environmental Sciences, University of KwaZulu-Natal,

South Africa. E-mail: takudzwamandizvo@gmail.com

Received: 21 May 2020; $\quad$ Accepted: 18 October 2020 
interest is rooted in the cumulative evidence that connects oxidative stress with premature seed aging.

Weber et al. (2005) reported that (i) storage product synthesis and (ii) molecular physiology of legume seed development are a dynamic processes characterized by overlapping of cell division and expansion as sequential waves. Relative to phytate loading, seeds progress through three main stages of development. Post-haste flowering, seed development is dominated by rapid karyokinesis before a storage phase when phytate is loaded in expanded cells. Oxidative stress is a common abiotic related problem that affects seeds in maturation phase when seed tissues undergo dehydration and viability. Chibarabada et al. (2015) reported higher levels of phenolics and drought tolerance in dark coloured Bambara groundnut seeds compared to light coloured seeds. However, the results were limited to phenolics and are therefore not representative of phytic acid which has a novel role in seed protection against oxidative stress (Pilu et al., 2005).

The metabolism of phytic acid by seed plants has been previously examined in common bean (Phaseolus vulgaris) (Urbano et al., 2000), lettuce (Lactuca sativa) (Nasri et al., 2011) and wheat (Triticum aestivum) (Pilu et al., 2003). There have been few attempts to examine the metabolism of phytic acid in developing system, and some of these attempts were hampered by the lack of accurate methods of staging embryo development (Walker, 1974). Although extensive research has been carried out on phytic acid with mature or dormant germinating seeds, no single study exists which adequately deals with metabolism of phytic acid in developing Bambara groundnut.
The objective of this study was to determine the pattern of phytic acid accumulation in developing Bambara groundnut landraces of different seed coat colour. We do not know if the phytic acid accumulation rate in Bambara groundnut is seed coat colour dependent. As a first step to address the issue, we examined the simultaneous changes in phytic acid indirectly by measuring total extractable phosphorus during seed development. Spectrophotometry chemical analysis technique was used as the investigation probe.

\section{MATERIALS AND METHODS}

\section{Plant material}

Bambara groundnut landraces (Mana, Kazai, Kazuma, and G340A) were sourced from the Department of Research and Specialist Services (DR\&SS). The seeds were planted on 27 November 2017 in the irrigated area of the University of KwaZulu-Natal located at Ukulinga Research farm (29 40'1.65"S, 30²4'28.61'E). Planting was done on clay loamy soil containing $142 \mathrm{mg} \mathrm{kg-}{ }^{1}$ extractable soil $\mathrm{P}$ in a completely randomized block design replicated three times (Figure 1). Each plot measured $(2.5 \times 2 \mathrm{~m})$, with in-row and inter-row spacing of $(0.3 \times 0.45 \mathrm{~cm})$ respectively. Weeding and earthing was done by hand-hoe, irrigation was done using overhead sprinklers during periods of dry spells. Subsequent rainfall was adequate to prevent drought stress and to sustain adequate growth throughout the growing season.

\section{Seed sampling}

Due to the multiple and indeterminate flowering habit of Bambara groundnut, the following procedures were used to obtain seed samples of carefully defined maturation. On

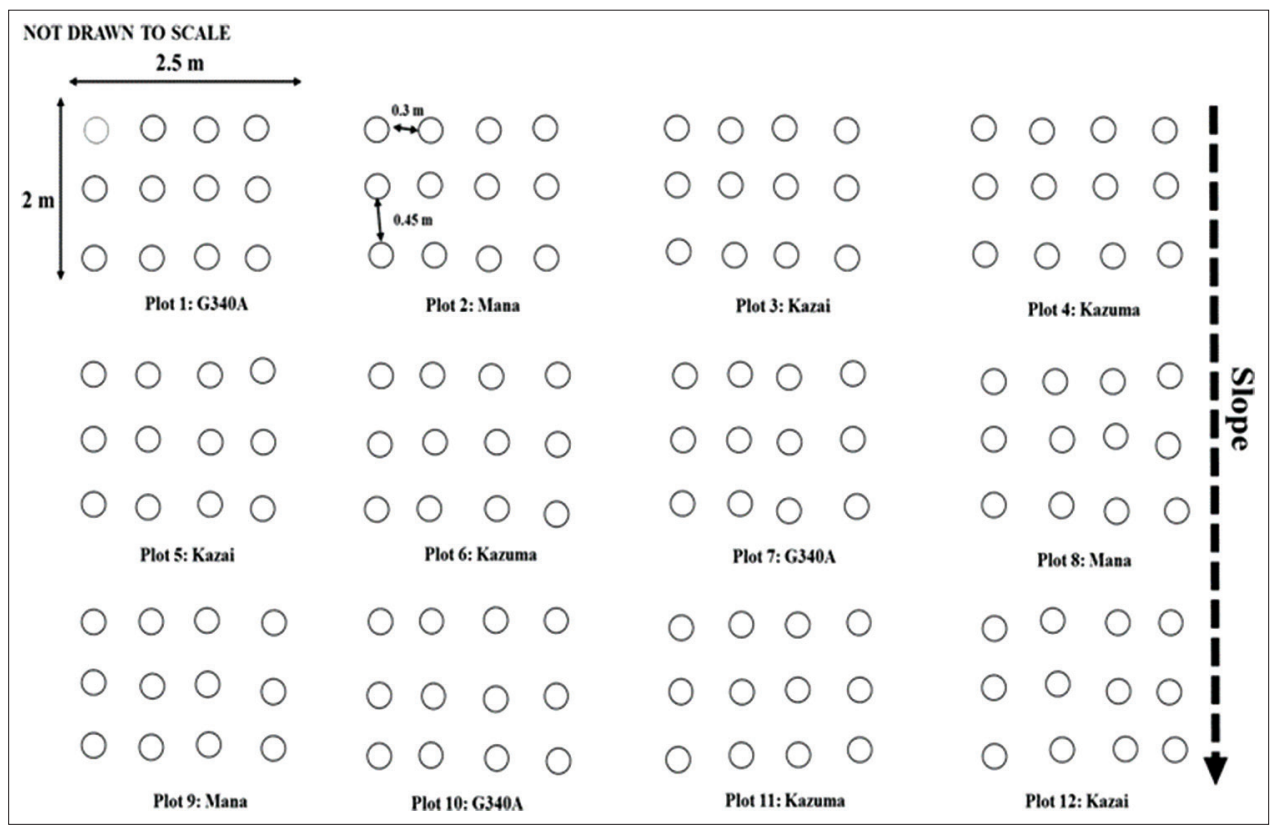

Fig 1. Field experimental layout of plots blocked against slope gradient 
the day flowers opened, the peduncles were tagged using a string. Sections of rows $2 \mathrm{~m}$ in length were selected at random, and large samples of pods were harvested five times at weekly intervals beginning 14 days after flowering. Harvested pods at each sampling interval were washed with water and shelled. Fresh and dry mass of developing embryos were measured using an analytical scale (Presica 125A) before and after cryodesiccation respectively. The developing embryo (seed) (Figure 2) were lyophilized using freeze drier (Larry Virtis $255 \mathrm{~L})$ at $\left(-126.5^{\circ} \mathrm{C}\right)$ for 96 hours. Dried seeds were ground into fine powder using mortar and pestle and stored in a chest freezer at $-5{ }^{\circ} \mathrm{C}$ before phosphate extraction.

\section{Determination of available phosphorus}

The determination of available phosphorus in developing seeds was done using the ascorbic acid colour development method (Schoenau and O'Halloran, 2008). The ascorbic acid method (Figure 3) is reliable for determination of phosphorus and, moreover, less subjective to interference in colour development, and colour is stable for about 24 hours.

\section{Preparation of extractant}

Extraction solutions sodium bicarbonate $\left(\mathrm{NaHCO}_{3(\mathrm{~s})}\right)$, sulphuric acid $\left(\mathrm{H}_{2} \mathrm{SO}_{4(\mathrm{~s})}\right)$, ammonium molybdate $\left(\left(\mathrm{NH}_{4}\right)_{6} \mathrm{Mo}_{7} \mathrm{O}_{24(\mathrm{~s})}\right)$, ascorbic acid $\left(\mathrm{C}_{6} \mathrm{H}_{8} \mathrm{O}_{6(\mathrm{~s})}\right)$ and antimony tartrate $\left(\mathrm{C}_{8} \mathrm{H}_{10} \mathrm{~K}_{2} \mathrm{O}_{15} \mathrm{Sb}_{2(\mathrm{~s})}\right)$ were prepared following method by (Mussa et al., 2009; Ozyurek et al., 2007; Pote and Daniel, 2000). Colour solution was prepared by adding $30 \mathrm{ml}$ of ammonium molybdate solution and $10 \mathrm{ml}$ of antimony solution to $100 \mathrm{ml}$ of $5 \mathrm{~N} \mathrm{H} 2 \mathrm{SO} 4$.

\section{Phosphorus standards}

Stock solution was made by dissolving $0.4390 \mathrm{~g} \mathrm{KH}_{2} \mathrm{PO}_{4}$ in 400 $\mathrm{ml}$ distilled water in a 1 litre volumetric flask, $25 \mathrm{ml}_{7} 7 \mathrm{~N} \mathrm{H}_{2} \mathrm{SO}_{4}$ (that is $9.5 \mathrm{ml} \mathrm{H}_{2} \mathrm{SO}_{4}$ made up to $50 \mathrm{ml}$ ) were added and made up to the volume mark with distilled water. This gave a stock solution containing $100 \mathrm{mg} / \mathrm{l}$ phosphorus. The linearity of phosphorus concentration versus absorbance was calibrated by list of working standard concentrations in (Table 1).

\section{Spectrophotometry procedure}

One gram of freeze-dried seed samples was weighed in a $30 \mathrm{ml}$ Erlenmeyer flask, $50 \mathrm{ml}$ of $0.5 \mathrm{M} \mathrm{NaHCO}_{3}$ solution were added. The mixture was shaken on a reciprocal shaker (Heidolph REAX 2000) at $6000 \mathrm{rpm}$ for 30 minutes. The mixture was filtered through Whatman No. 5 filter paper, $1 \mathrm{ml}$ of aliquot of seed filtrate was pipetted into a test tube. Distilled water $(8 \mathrm{ml})$, colour solution $(1 \mathrm{ml})$ and ascorbic acid $(0.5 \mathrm{ml})$ were added to $1 \mathrm{ml}$ seed filtrate. The mixture was shaken on a vortex shaker and left to stand for 15 minutes. Standard P curve was calibrated by pipetting $1 \mathrm{ml}$ of each of the $0,0.2$, 0.5, 1.0, 2.0, 4.0, and $8.0 \mathrm{ppm}$ standard P working solutions respectively in 7 test tubes. Eight millilitres of distilled water, 1 ml of colour solution and $0.5 \mathrm{ml}$ of ascorbic acid solution were added to each standard P solutions. The measure the colour intensity was done after 15 minutes using a spectrophotometer (UV-Vis 2000 model) with quartz cuvette at wavelength of $720 \mathrm{~nm}$. A standard curve of spectrophotometer absorbance was plotted against the $\mathrm{P}$ concentrations.

The molybdenum reaction occurred in two stages; first stage involves the formation of a Keggin ion around the

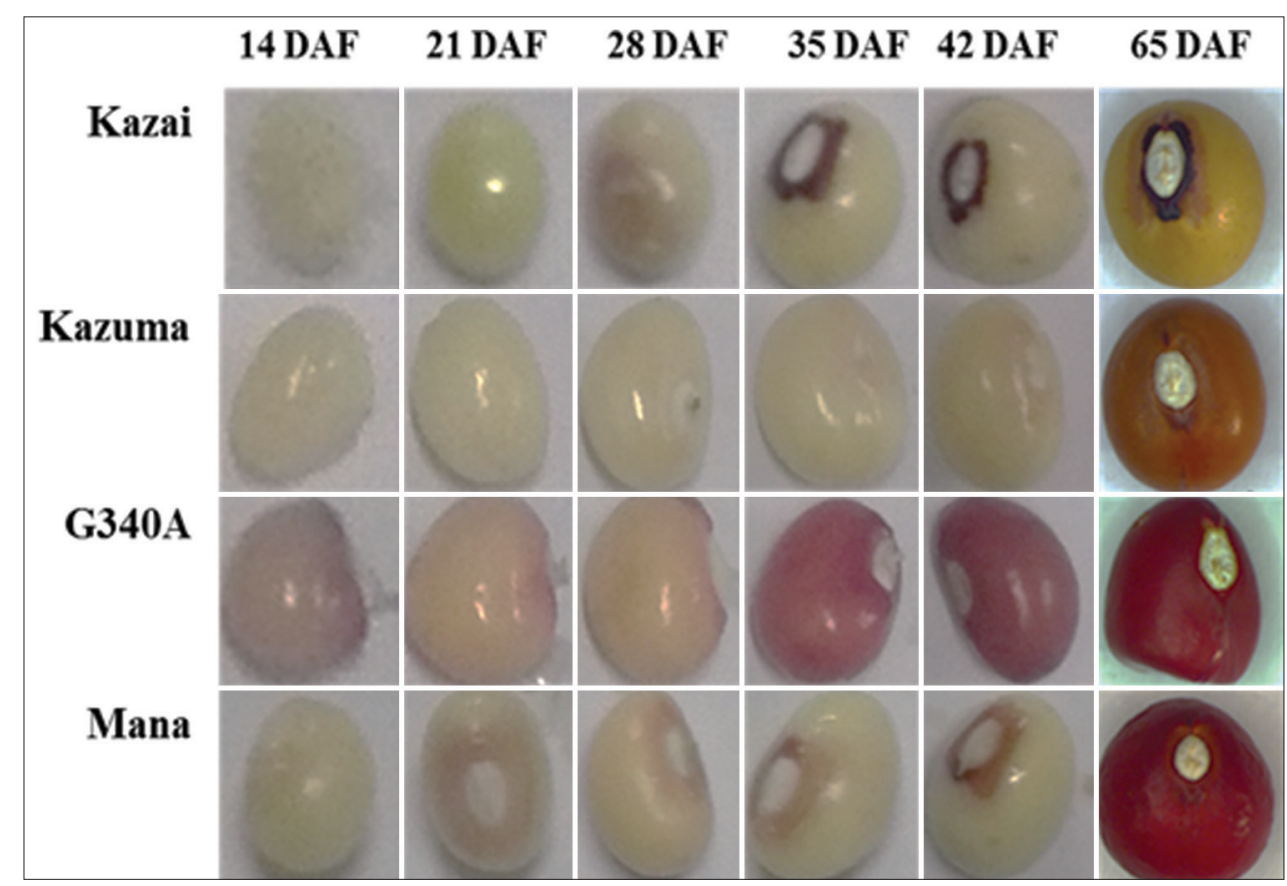

Fig 2. Bambara groundnut seeds sampled at different days after flowering by destructive sampling 


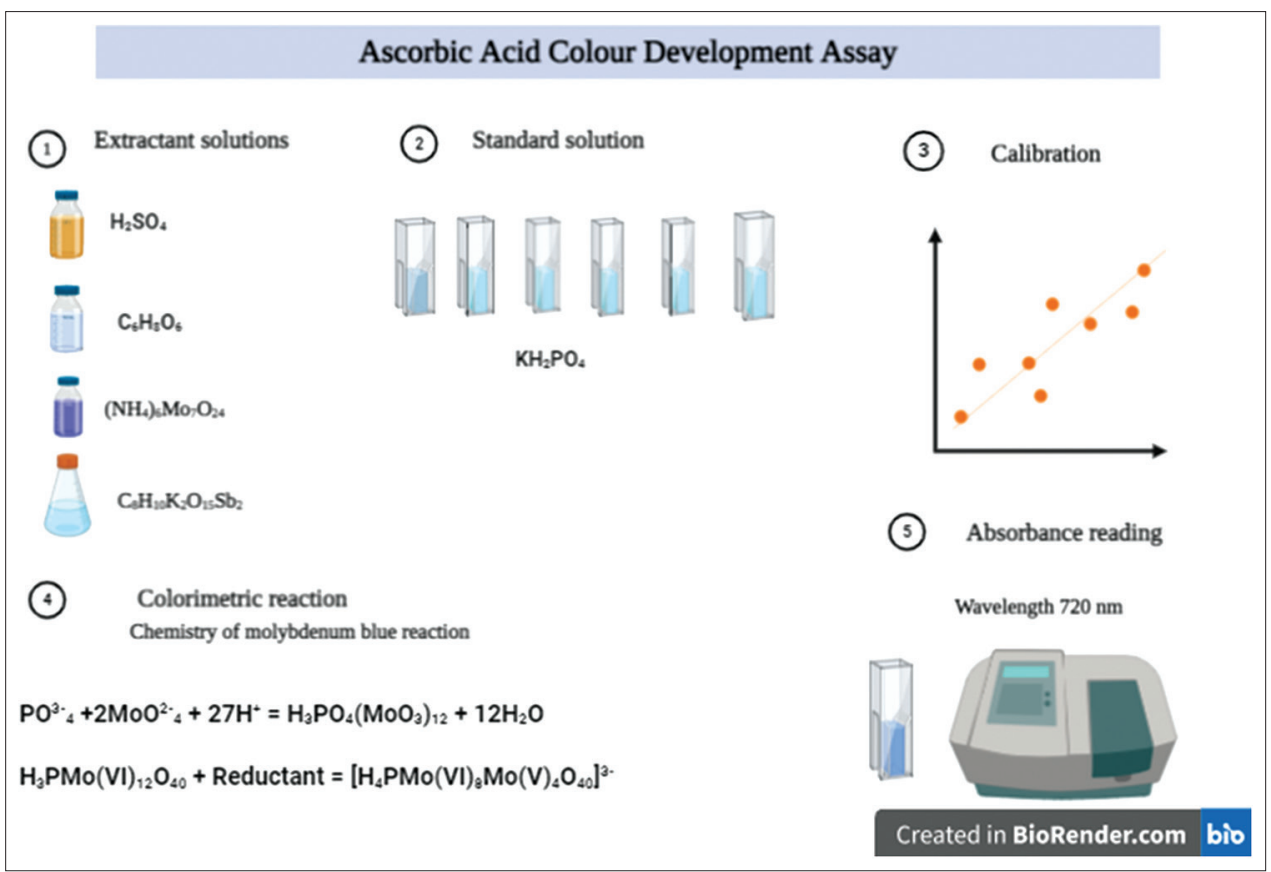

Fig 3. Schematic illustration of the ascorbic acid method used to quantify phosphorus in Bambara groundnut seeds

Table 1: Working standard concentrations and volumes of stock standard solution

\begin{tabular}{lcccccccccc}
\hline & \multicolumn{4}{c}{ Working standard concentration $(\mathbf{m g} / \mathbf{l})$} & \multicolumn{4}{c}{ Volume of stock standard solution (ml) } \\
\hline Analyte & L1 & L2 & L3 & L4 & L5 & L1 & L2 & L3 & L4 & L5 \\
Phytate & 0.10 & 0.50 & 1.00 & 5.00 & 10.00 & 0.01 & 0.05 & 0.10 & 0.50 & 1.00 \\
\hline
\end{tabular}

analyte anion and the second stage entails the reduction of the heteropoly acid to form a deeply blue-coloured product. These stages are described in simplified forms shown in equations (1) and (2) (Nagul et al., 2015);

$\mathrm{PO}^{3}-4+2 \mathrm{MoO}^{2}-4+27 \mathrm{H}+\rightarrow \mathrm{H}_{3} \mathrm{PO}_{4}\left(\mathrm{MoO}_{3}\right)_{12}+12 \mathrm{H}_{2} \mathrm{O}$

$\mathrm{H}_{3} \mathrm{PMo}(\mathrm{VI})_{12} \mathrm{O}_{40}+$ Reductant $\rightarrow\left[\mathrm{H}_{4} \mathrm{PMo}(\mathrm{VI})_{8} \mathrm{Mo}(\mathrm{V})_{4} \mathrm{O}_{40}\right]^{3-}$

\section{Phosphorous calculations}

Available phosphorus content was calculated using the formula according to (Dijk, 2007):

Available P $(\mathrm{mg} / \mathrm{kg})=\mathrm{C} \times$ Dilution Factor

Where: $\mathrm{C}=$ Phosphorus concentration from equation

\section{Statistical analysis}

The data were subjected to a one-way analysis of variance (ANOVA) and the significance of difference between means was determined by Duncan's multiple range test $(\mathrm{P}<0.05)$ using the Genstat $18^{\text {th }}$ edition statistical software. Descriptive statistics for phosphorous concentration were computed using XLSTAT 2020.1.2.65042.

\section{RESULTS}

\section{Standard curve}

The absorbencies was determined at $720 \mathrm{~nm}$ using solution of $\mathrm{KH}_{2} \mathrm{PO}_{4}$ at nine concentrations in order to test whether there is a linear relation between concentration and absorbance. Since the absorbance were linear $\left(\mathrm{r}^{2}=0.9983\right)$ over the concentration range used the absorption coefficients could be determined from (Figure 4).

Absorbance is dependent on $\mathrm{P}$ concertation and varies between 0.0195 for $\mathrm{P}=5 \mathrm{ppm}$ and 2.753 for $\mathrm{P}=75 \mathrm{ppm}$. The curve giving the relation between concentration and absorbance is given in (Figure 4).

\section{Absorbance}

Spectrophotometric measurements of absorbance were significantly different $(\mathrm{P}<0.05)$ (Table 2$)$. The absorbance of chromophore increased with days after flowering (DAF). The absorbance at 14 DAF varied from 0.054 in Kazai to 0.205 in G340A. Absorbance greatly increased to reach 1.157 in G340A and 0.780 in Kazai at 65 DAF.

Repeatability (within-run precision) and reproducibility (between-run precision) were estimated by regression analysis $\left(\mathrm{R}^{2}=0.9983\right)$. 


\section{Phosphorus concentration}

There were significant differences in available phosphorus among developing landrace seeds $(\mathrm{P}<0.05)$ (Figure 5). The amount of phosphorus in developing seeds increased gradually from $14 \mathrm{DAF}$ to $42 \mathrm{DAF}$. On $14 \mathrm{DAF}$, the highest and lowest phosphorus were observed in G340A (5.69 $\left.\mathrm{mgkg}^{-1}\right)$ and Kazai $\left(1.51 \mathrm{mgkg}^{-1}\right.$ ) respectively (Figure 6). The concentration of phosphorus was highest in G340A (32.23 $\left.\mathrm{mgkg}^{-1}\right)$ and lowest in Kazai (21.73 $\left.\mathrm{mgkg}^{-1}\right)$ at physiological maturity (65 DAF).

\section{DISCUSSION}

Most of the inorganic phosphorus (Pi) (80\%) present in mature legume seeds is stored as phytate (Bilyeu et al., 2008; Mandizvo and Odindo, 2019). Raboy and Dickinson (1987) reported that all of the $P$ translocated to developing seeds is incorporated into phytic acid from 21 DAF until physiological maturity. Ficco et al. (2009) reported a linear relationship between phytic acid measured using HPLC and Pi measured by colorimetric assay in wheat seeds (Figure 7). Therefore, the method used to quantify phytic acid in developing seeds is based on the fact that phytic acid is the storage compound of phosphorus in seeds.

The colour complexes obeyed Beer-Lambert's law over a range (0-75 ppm) of prepared phosphorus standards to give a linear calibration curve (Figure 4). The Beer Lambert law states that "absorbance is directly proportional to the concentration of the solution of the sample used in the experiment" (Mangkuto and Soelami, 2017). The mechanism of the reaction is based on the reduction of $\mathrm{Mo}(\mathrm{VI})$ to $\mathrm{Mo}(\mathrm{V})$ by the sample analyte and subsequent formation of coloured phosphomolybdenum blue complex at acidic $\mathrm{pH}$. The formation of a bluecoloured complex of phosphate and $\mathrm{Mo}(\mathrm{V})$ was presented as the basis of a spectrophotometric method to determine inorganic phosphate (John, 1970). This method was later revised and modified by (McKie and McCleary, 2016).
Our results show a gradual increase in phosphorus concentration from $14 \mathrm{DAF}$ to $42 \mathrm{DAF}$, this is in accordance to Iwai et al. (2012), who reported a rapid increase in seed P levels after flowering. During the grain-filling stage, plants remobilize and transport nutrients distributed throughout the vegetative source organs into seeds. Plant seeds contain large amounts of phosphorus, which will support growth during the early stages of seedling development. Iwai et al.

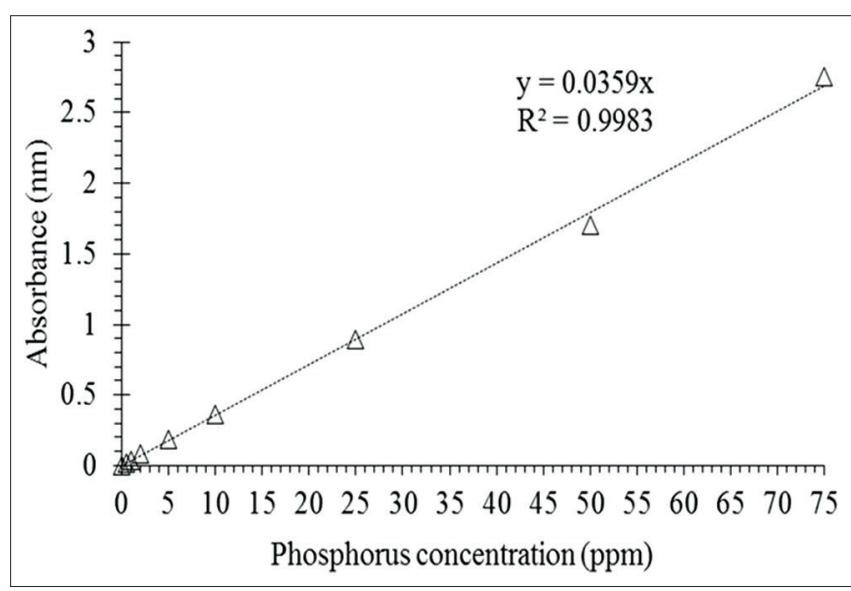

Fig 4. Standard curve showing the linear response between absorbance and phosphorous concentration

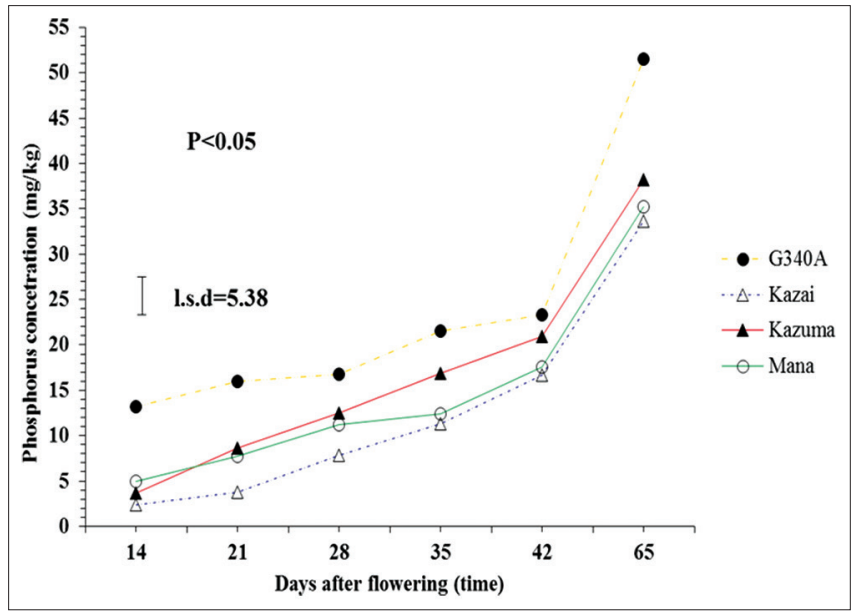

Fig 5. Trend of phosphorus concentration in developing Bambara groundnut seeds (from 14 to $65 \mathrm{DAF}$ )

Table 2: Mean absorbance values for Bambara groundnut landraces from early embryogenesis to physiological maturity

\begin{tabular}{|c|c|c|c|c|c|c|}
\hline \multirow[t]{2}{*}{ Bambara landrace } & \multicolumn{6}{|c|}{ Absorbance $(720 \mathrm{~nm})$} \\
\hline & 14 DAF & 21 DAF & 28 DAF & 35 DAF & 42 DAF & 65 DAF \\
\hline G340A & $0.205^{\mathrm{a}}$ & $0.270^{\mathrm{a}}$ & $0.390^{\mathrm{a}}$ & $0.449^{a}$ & $0.540^{\mathrm{a}}$ & $1.157^{\mathrm{a}}$ \\
\hline Kazai & $0.054^{d}$ & $0.087^{d}$ & $0.182^{d}$ & $0.262^{d}$ & $0.386^{d}$ & $0.780^{d}$ \\
\hline Kazuma & $0.085^{c}$ & $0.199^{b}$ & $0.289^{b}$ & $0.391^{b}$ & $0.485^{b}$ & $0.887^{b}$ \\
\hline Mana & $0.115^{b}$ & $0.181^{\mathrm{C}}$ & $0.259^{c}$ & $0.288^{c}$ & $0.408^{c}$ & $0.818^{c}$ \\
\hline P-value & $<.001$ & $<.001$ & $<.001$ & $<.001$ & $<.001$ & $<.001$ \\
\hline s.e.d & $3.96 \times 10^{-3}$ & $3.13 \times 10^{-3}$ & $3.22 \times 10^{-3}$ & $1.885 \times 10^{-2}$ & $2.90 \times 10^{-3}$ & $1.12 \times 10^{-2}$ \\
\hline LSD & $8.64 \times 10^{-3}$ & $6.81 \times 10^{-3}$ & $7.02 \times 10^{-3}$ & $4.107 \times 10^{-2}$ & $6.32 \times 10^{-3}$ & $2.44 \times 10^{-2}$ \\
\hline $\mathrm{cV} \%$ & 4.900 & 2.400 & 1.600 & 3.700 & 1.900 & 1.700 \\
\hline
\end{tabular}

*Means in the same column followed by the same letter are not significantly different, while means with different letters are significantly different according to Fisher's test $(\mathrm{P}<0.05)$ 


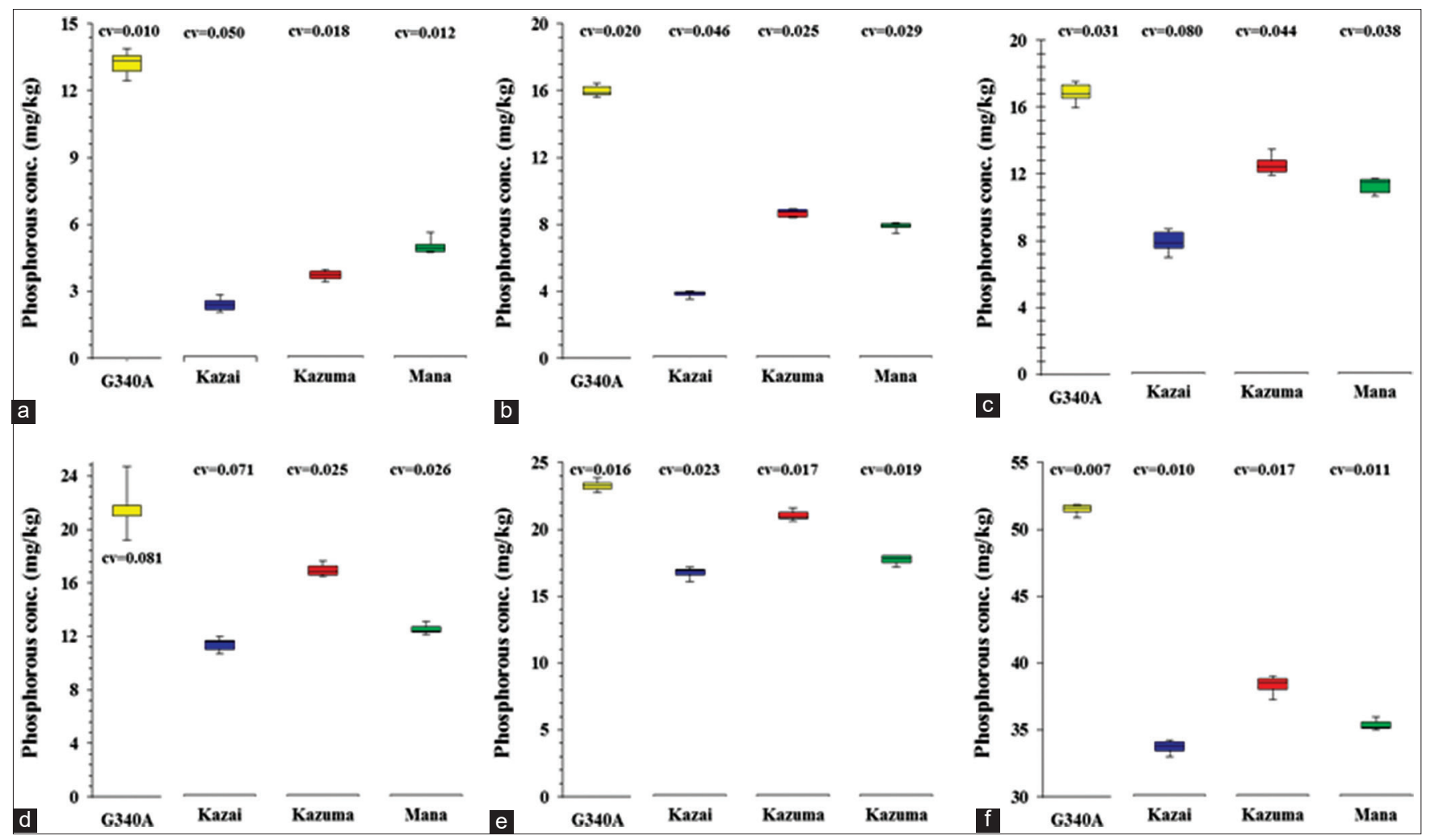

Fig 6. Box and whisker plots showing descriptive statistics of phosphorus concentration among Bambara groundnut landraces (a) 14 DAF, (b) $21 \mathrm{DAF}$, (c) $28 \mathrm{DAF}$, (d) $35 \mathrm{DAF}$, (e) $42 \mathrm{DAF}$ and (f) $65 \mathrm{DAF}$

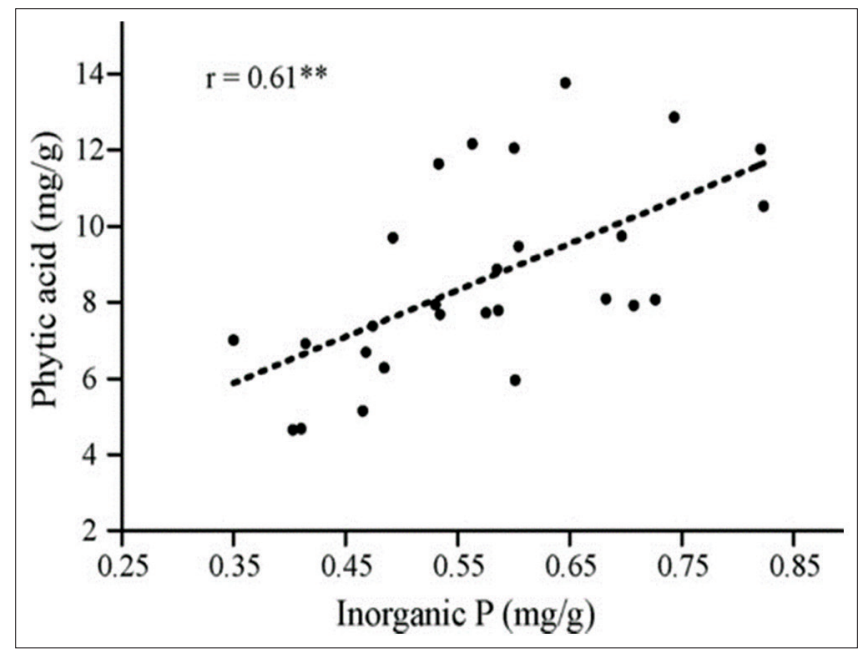

Fig 7. Relationship between phytic acid measurements by HPLC and Pi content obtained by colorimetric assay

(2012) reported that most of the P in seeds is stored in the form of phytic acid.

Highest accumulation rate and amount of phosphorus at physiological maturity (65 DAF) were observed in G340A (Figure 5). There are many factors affecting the different values in phosphorus including soil type, fertilizer application, irrigation conditions and genetics (Dost and Tokul, 2006). However according to our study, other factors (soil type, fertilizer application and irrigation conditions) were the same. Therefore the differences in phosphorus content values are strongly attributed to variation in genetics of landraces used. With the current soil nutrient status (nutrient impoverished soils) in SubSaharan Africa (Soropa et al., 2019), it is commendable for crop breeders to select for high phytic acid content in seeds. High phytic acid in seeds will improve seed germination and vigour under nutrient deficient soils. Before newly emerged seedlings switch from heterotrophs to autotrophs, they depend on food and mineral reserves of their parent seeds.

Based on the strong correlation between phytic acid and phosphorus in chickpea (Cicer arietinum) (Zhawar et al., 2011), soybean (Gycine max) (Zhang et al., 2007), common bean (Phaseolus vulgaris L.) (Walker, 1974) and cereals (Doria et al., 2009; Jennings and Morton, 1963; Karner et al., 2004; Williams, 1970), we partially conclude that G340A had the highest concentration of phytic acid. Phytic acid has implications in imparting drought tolerance and seed desiccation tolerance. In cowpea (Vigna unguiculata) Manavalan et al. (2009) reported that phytic acid accumulate during seed maturation add in initial recuperation of the crop from adverse effects of water stress. This was further supported with studies by (JoshiSaha and Reddy, 2015) and (Dhole and Reddy, 2016) using 
chickpea (Cicer arietinum L.) and mungbean (Vigna radiata L. Wilczek) respectively.

\section{CONCLUSION}

This study has revealed a possibility that phytic acid accumulation in developing Bambara groundnut landraces differ significantly. Based on the results of this study, the landrace G340A has highest concentration of phosphorus (equated to phytic acid) at physiological maturity and Kazai has the least concentration. These findings reset the debate on how phytic acid impact seed quality parameters which are (1) seed desiccation tolerance at physiological maturity and (2) seedling vigour during early establishment. Hence more studies should be done by designing experiments that investigate the impact of phytic acid on physiological seed quality. A rapid colour test has been adapted for the quantitative determination of total extractable phosphorus in developing seeds giving an idea of phytic acid levels at each development stage. However, it is recommended to repeat the experiment using sophisticated instruments such as high performance liquid chromatography (HPLC) gas chromatography (GC) with ability to separate isomers of phytic acid.

\section{ACKNOWLEDGEMENTS}

The Department of Research and Specialist Services (DR\&SS) Zimbabwe is acknowledged for providing Bambara groundnut landraces used in the study. To Mr. Tawanda Mandizvo, your vast expertise in Biorender application [https://app.biorender.com/] (Biorender, 2020) was instrumental in driving this project to success.

\section{Author's contribution}

Takudzwa Mandizvo planted the trial, collected data and did laboratory experiments and wrote the manuscript. Alfred Oduor Odindo analysed the data and reviewed the manuscript.

\section{REFERENCES}

Bailly, C. 2004. Active oxygen species and antioxidants in seed biology. Seed Sci. Res. 14: 93-107.

Bilyeu, K. D., P. Zeng, P. Coello, Z. J. Zhang, H. B. Krishnan, A. Bailey, P. R. Beuselinck and J. C. Polacco. 2008. Quantitative conversion of phytate to inorganic phosphorus in soybean seeds expressing a bacterial phytase. Plant Physiol. 146: 468-477.

Biorender. 2020. Biorender Templates and Illustrations, Biorender. Available from: https://www.app.biorender.com.

Bohn, L., L. Josefsen, A. S. Meyer and S. K. Rasmussen. 2007. Quantitative analysis of phytate globoids isolated from wheat bran and characterization of their sequential dephosphorylation by wheat phytase. J. Agric. Food Chem. 55: 7547-7552.
Chibarabada, T. P., A. T. Modi and T. Mabhaudhi. 2015. Bambara groundnut (Vigna subterranea) seed quality in response to water stress on maternal plants. Acta Agric. Scand. Sec. B Soil Plant Sci. 65: 364-373.

Dhole, V. J. and K. S. Reddy. 2016. Association of phytic acid content with biotic stress tolerance in mungbean (Vigna radiata L. Wilczek). Phytoparasitica. 44: 261-267.

Dijk, D. V. 2007. Wageningen evaluating programmes for analytical laboratories (Wepal): A world of experience. Commun. Soil Sci. Plant Anal. 33: 2457-2465.

Doria, E., L. Galleschi, L. Calucci, C. Pinzino, R. Pilu, E. Cassani and E. Nielsen. 2009. Phytic acid prevents oxidative stress in seeds: Evidence from a maize (Zea mays L.) low phytic acid mutant. J. Exp. Bot. 60: 967-978.

Dost, K. and O. Tokul. 2006. Determination of phytic acid in wheat and wheat products by reverse phase high performance liquid chromatography. Anal. Chim. Acta. 558: 22-27.

Ficco, D. B. M., C. Riefolo, G. Nicastro, V. De Simone, A. M. Di Gesu, R. Beleggia, C. Platani, L. Cattivelli and P. De Vita. 2009. Phytate and mineral elements concentration in a collection of Italian durum wheat cultivars. Field Crops Res. 111: 235-242.

Iwai, T., M. Takahashi, K. Oda, Y. Terada and K. T. Yoshida. 2012. Dynamic changes in the distribution of minerals in relation to phytic acid accumulation during rice seed development. Plant Physiol. 160: 2007-2014.

Jennings, A. C. and R. K. Morton. 1963. Changes in nucleic acids and other phosphorus-containing compounds of developing wheat grain. Aust. J. Biol. Sci. 16: 332-341.

John, M. K. 1970. Colorimetric determination of phosphorus in soil and plant materials with ascorbic acid. Soil Sci. 109: 214.

Joshi-Saha, A. and K. S. Reddy. 2015. Repeat length variation in the 5'UTR of myo-inositol monophosphatase gene is related to phytic acid content and contributes to drought tolerance in chickpea (Cicer arietinum L.). J. Exp. Bot. 66: 5683-5690.

Karner, U., T. Peterbauer, V. Raboy, D. A. Jones, C. L. Hedley and A. Richter. 2004. myo-Inositol and sucrose concentrations affect the accumulation of raffinose family oligosaccharides in seeds. J. Exp. Bot. 55: 1981-1987.

Lehrfeld, J. 1994. HPLC separation and quantitation of phytic acid and some inositol phosphates in foods: Problems and solutions. J. Agric. Food Chem. 42: 2726-2731.

Manavalan, L. P., S. K. Guttikonda, L. S. Tran and H. T. Nguyen. 2009. Physiological and molecular approaches to improve drought resistance in soybean. Plant Cell Physiol. 50: 1260-1276.

Mandizvo, T. and A. O. Odindo. 2019. Seed mineral reserves and vigour of Bambara groundnut (Vigna subterranea L.) landraces differing in seed coat colour. Heliyon. 5: e01635.

Mangkuto, R. A. and F. X. N. Soelami. 2017. Photometric and colorimetric measurements of luminaires using goniometer and spectrophotometer in a dark chamber. Proc. Eng. 170: 226-233.

Martínez-Ballesta, M. D. C., C. Egea-Gilabert, E. Conesa, J. Ochoa, M. J. Vicente, J. A. Franco, S. Bañon, J. J. Martínez and J. A. Fernández. 2020. The importance of ion homeostasis and nutrient status in seed development and germination. Agronomy. 10: 504.

McKie, V. A. and B. V. McCleary. 2016. A novel and rapid colorimetric method for measuring total phosphorus and phytic acid in foods and animal feeds. J. AOAC Int. 99: 738-743.

Mussa, S. B., H. S. Elferjani, F. A. Haroun and F. F. Abdelnabi. 2009. Determination of available nitrate, phosphate and sulfate in soil samples. Int. J. PharmTech Res. 1: 598-604.

Nagul, E. A., I. D. McKelvie, P. Worsfold and S. D. Kolev. 2015. The molybdenum blue reaction for the determination of 
orthophosphate revisited: Opening the black box. Anal. Chim. Acta. 890: 60-82.

Nasri, N., R. Kaddour, M. Rabhi, C. Plassard and M. Lachaal. 2011. Effect of salinity on germination, phytase activity and phytate content in lettuce seedling. Acta Physiol. Plant. 33: 935-942.

Ozyurek, M., K. Guclu, B. Bektasoglu and R. Apak. 2007. Spectrophotometric determination of ascorbic acid by the modified CUPRAC method with extractive separation of flavonoids-La(III) complexes. Anal. Chim. Acta. 588: 88-95.

Pilu, R., M. Landoni, E. Cassani, E. Doria and E. Nielsen. 2005. The maize Ipa241 mutation causes a remarkable variability of expression and some pleiotropic effects. Crop Sci. 45: 20962105.

Pilu, R., D. Panzeri, G. Gavazzi, S. K. Rasmussen, G. Consonni and E. Nielsen. 2003. Phenotypic, genetic and molecular characterization of a maize low phytic acid mutant (Ipa241). Theor. Appl. Genet. 107: 980-987.

Pote, D. and T. Daniel. 2000. Analyzing for dissolved reactive phosphorus in water samples. Methods of phosphorus analysis for soils, sediments, residuals, and waters. Southern Coop. Ser. Bull. 396: 91-93.

Raboy, V. 2001. Seeds for a better future: "Low phytate" grains help to overcome malnutrition and reduce pollution. Trends Plant Sci. 6: 458-462.
Raboy, V. and D. B. Dickinson. 1987. The timing and rate of phytic acid accumulation in developing soybean seeds. Plant Physiol. 85: 841-844.

Schoenau, J. and I. O'Halloran. 2008. Sodium Bicarbonate-extractable Phosphorus. Soil Sampling and Methods of Analysis.

Soropa, G., J. Nyamangara and E. Z. Nyakatawa. 2019. Nutrient status of sandy soils in smallholder areas of Zimbabwe and the need to develop site-specific fertiliser recommendations for sustainable crop intensification. South Afr. J. Plant Soil. 36: 149-151.

Urbano, G., M. Lopez-Jurado, P. Aranda, C. Vidal-Valverde, E. Tenorio and J. Porres. 2000. The role of phytic acid in legumes: Antinutrient or beneficial function? J. Physiol. Biochem. 56: 283-294.

Walker, K. A. 1974. Changes in phytic acid and phytase during early development of Phaseolus vulgaris L. Planta. 116: 91-98.

Weber, H., L. Borisjuk and U. Wobus. 2005. Molecular physiology of legume seed development. Annu. Rev. Plant Biol. 56: 253-279.

Williams, S. G. 1970. The role of phytic acid in the wheat grain. Plant Physiol. 45: 376-381.

Zhang, W. H., Y. C. Zhou, K. E. Dibley, S. D. Tyerman, R. T. Furbank and J. W. Patrick. 2007. Nutrient loading of developing seeds. Funct. Plant Biol. 34: 314-331.

Zhawar, V. K., N. Kaur and A. K. Gupta. 2011. Phytic acid and raffinose series oligosaccharides metabolism in developing chickpea seeds. Physiol. Mol. Biol. Plants. 17: 355-362. 